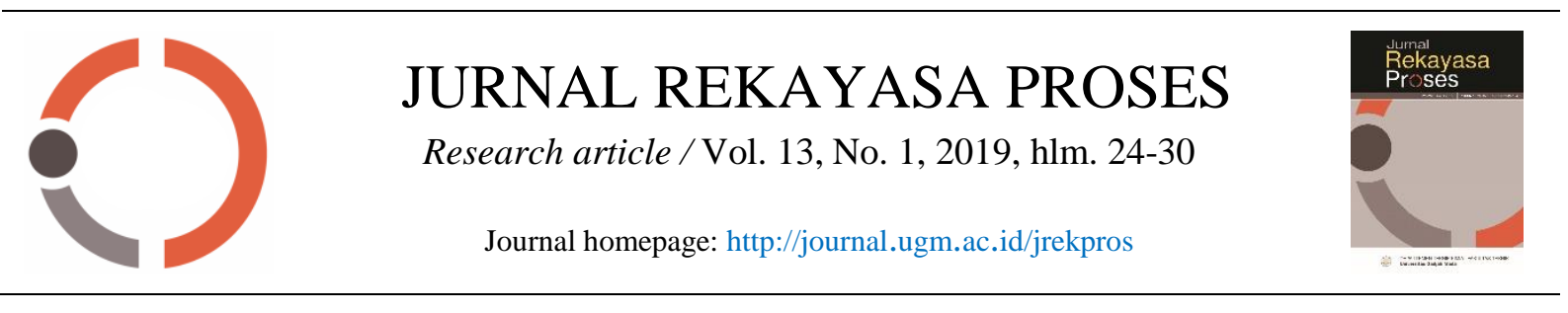

\title{
Pelarutan Emas pada Pelindian Konsentrat Emas Hasil Roasting Menggunakan Reagen Tiosianat
}

\author{
Fika Rofiek Mufakhir ${ }^{1 *}$, Jones Maima Sinaga ${ }^{2}$, Soesaptri Oediyani ${ }^{2}$, Widi Astuti ${ }^{1}$ \\ ${ }^{1}$ Balai Penelitian Teknologi Mineral, Lembaga Ilmu Pengetahuan Indonesia \\ J1 Ir. Sutami Km 15 LIPI, Lampung, 35361 \\ ${ }^{2}$ Program Studi Teknik Metalurgi, Fakultas Teknik, Universitas Sultan Ageng Tirtayasa \\ Kampus B UNTIRTA, Jalan Jenderal Sudriman Km.3, Banten, 42435 \\ *Alamat korespondensi: fika001@lipi.go.id/fika_cupiw@yahoo.com
}

(Submisi: 3 Desember 2018; Revisi: 3 Maret 2019; Penerimaan: 5 Maret 2019)

\begin{abstract}
A B S T R A C T
Dissolution of gold from roasting concentrate of gold ore using potassium thiocyanate with the presence of ferric chloride as an oxidizer was investigated. The concentrate was taken from Lengkukai gold mine. Gold ore particles under $53 \mu \mathrm{m}$ in size were roasted at varied temperature, separated using wet magnetic separator, and finally leached. The X-ray diffraction (XRD) analysis showed that there were phase changes after roasting with the emergence of new phases such as hematite, pyrrhotite, and almandine. Leaching of gold concentrate after roasting and magnetic separation showed that gold was in non-magnetic concentrate at $950^{\circ} \mathrm{C}$ with the highest gold dissolution of 0.95 $\mathrm{mg} / \mathrm{L}$, while magnet concentrate was completely absent. Experiments with the addition of $\mathrm{Fe}^{3+}$ ion oxidizers for 24-hour range did not have significant effect on gold dissolution. The highest gold concentration obtained of $2.29 \mathrm{mg} / \mathrm{L}$ was obtained at 12 hours with $0.1 \mathrm{M} \mathrm{FeCl}$. The increase of thiocyanate reagent concentrations, which showed a linear correlation to gold dissolution, produced up to $2.25 \mathrm{mg} / \mathrm{L}$ of gold concentration (12 hours at $0.3 \mathrm{M} \mathrm{KSCN}$ ).
\end{abstract}

Keywords: ferric ion gold dissolution; gold concentrate; roasting; thiocyanate

\section{A B S T R A K}

Pelarutan emas dari konsentrat hasil roasting bijih emas tambang Lengkukai menggunakan reagen pelindi kalium tiosianat dengan penambahan ferric chloride sebagai oksidator telah diteliti. Partikel bijih emas dengan ukuran di bawah $53 \mu \mathrm{m}$ di-roasting pada berbagai temperatur kemudian dipisahkan menggunakan pemisah magnetik basah dan akhirnya dilindi. Hasil analisis $X$-ray diffraction (XRD) menunjukkan adanya perubahan fase setelah roasting dengan munculnya fase-fase baru yaitu hematit, pirohitit dan almandin. Pelindian konsentrat emas hasil roasting dan pemisahan magnetik menunjukan emas berada pada konsentrat non magnet temperatur roasting $950{ }^{\circ} \mathrm{C}$ dengan pelarutan emas paling tinggi sebesar $0,95 \mathrm{mg} / \mathrm{L}$, berbeda dengan konsentrat magnet yang sama sekali tidak ada. Percobaan dengan penambahan oksidator ion $\mathrm{Fe}^{3+}$ selama rentang 24 jam tidak memberikan efek yang signifikan terhadap pelarutan emas. Dari penelitian ini didapatkan konsentrasi emas tertinggi sebesar 2,29 mg/L pada 12 jam dengan konsentrasi $\mathrm{FeCl}_{3} 0,1 \mathrm{M}$. Sedangkan penambahan konsentrasi reagen tiosianat, yang menunjukan hubungan linier terhadap pelarutan emas, menghasilkan konsentrasi besar hingga $2,25 \mathrm{mg} / \mathrm{L}$ selama 12 jam pada konsentrasi KSCN 0,3 M.

Kata kunci: ion besi III; konsentrat emas; pelarutan emas; roasting; tiosianat 


\section{Pendahuluan}

Menurut laporan Gold Fields Mineral Services (GFMS), Thomson Reuters tahun 2016, Indonesia merupakan negara produsen emas terbesar ke-2 Asia setelah Cina. Sumber daya bijih emas primer diperkirakan berjumlah 9,86 milyar ton (ESDM, 2017) dan memiliki potensi sangat besar untuk diolah. Untuk mendapatkan hasil yang efektif, teknologi pengolahan emas harus selalu memperhatikan karakteristik dari setiap tipe bijih emas. Umumnya tambang emas skala besar masih menggunakan reagen garam sianida $(\mathrm{NaCN} / \mathrm{KCN})$ yang dikenal sebagai proses sianidasi untuk mengikat ion emas menjadi ion emas komplek atau aurosianid $\left(\mathrm{AuCN}^{-}\right)$. Aurosianid dipilih karena sangat efektif untuk tipe free gold maupun free milling dari bijih emas aluvial maupun oksida setelah melalui tahap kominusi dan konsentrasi. Namun apabila proses pelindian tidak terkontrol dengan baik, $\mathrm{pH}$ yang terlalu tinggi (> pH 12,5) menyebabkan perlambatan kinetika reaksi pelindian dan apabila terlalu rendah $(<\mathrm{pH} 9,4)$ akan terjadi kehilangan ion sianida $\left(\mathrm{CN}^{-}\right)$menjadi gas sianida $(\mathrm{HCN})$ yang sangat beracun (Yannopolous, 1991). Potensial reduksi-oksidasi yang lebih rendah membutuhkan proses yang lebih panjang dan mahal karena memerlukan beberapa tahap proses dari netralisasi sampai mendapatkan kondisi asam yang siap untuk umpan proses electrowinning sehingga tidak efektif untuk pelindian langsung bijih emas tipe sulfida (Handayani, 2017) maupun tipe refraktori. Selain itu, residu atau limbah yang dihasilkan memiliki toksisitas yang tinggi bila tidak ditangani dengan baik. Residu yang dihasilkan sangat berbahaya bagi pekerja dan mahluk hidup sekitar, sehingga penggunaan reagen ini menjadi masalah lingkungan.

Beberapa reagen pengganti sudah banyak diteliti seperti thiocyanate (Li dkk., 2012), thiourea (Orgul dan Atalay, 2002), thiosulphate (Feng dan Deventer, 2007; 2011; Feceriova dkk., 2009), iodide/iodine (Baghalha M, 2012), dan lain-lain. Tiosianat (SCN) merupakan alternatif yang baik karena merupakan reagen asam stabil yang dapat digunakan untuk pelarutan emas dalam lingkungan asam sehingga tidak diperlukan lagi proses netralisasi. Sistem tiosianat memberikan hasil sama baiknya dengan sianida namun jauh lebih baik daripada tiourea yaitu pada konsumsi $\mathrm{SCN}(<1 \mathrm{~kg} / \mathrm{t})$ dengan ekstraksi emas maksimal antara 92-96\% selama 24 jam (Monhemius dan Ball, 1995). Potensi penggunaan tiosianat menjadi pertimbangan dalam pelindian emas, karena toksisitas jauh lebih rendah daripada garam sianida (Adams, 2005). Pelindian dengan tiosianat membutuhkan oksidator yang tepat untuk menjaga kestabilan ion tiosianat $\left(\mathrm{SCN}^{-}\right)$. Oksidator ferric ion $\left(\mathrm{Fe}^{3+}\right)$ dipilih karena dapat meningkatkan stabilitas $\mathrm{SCN}^{-}$dibandingkan dengan oksigen yang membuat laju pelarutan sangat lambat sehingga menyebabkan tiosianat sangat cepat teroksidasi oleh hidrogen peroksida (Marsden dkk., 2009).

Tipe emas sulfida maupun refraktori tidak dapat langsung diolah melalui jalur pelindian karena mineral sulfida, yang paling sering muncul adalah pirit $\left(\mathrm{FeS}_{2}\right)$, tidak mudah larut dalam larutan asam sehingga diperlukan proses pra-pengolahan. Salah satu metode prapengolahan yang telah digunakan bertahun-tahun adalah pemanggangan (roasting). Untuk sebagian tipe refraktori sebelum, pra-pengolahan beberapa tahapan kominusi perlu dilakukan, hingga partikel emas atau mineral yang menyelimutinya dapat terliberasi dari mineral induk. Prapengolahan dengan roasting sangat efektif untuk mengolah bijih sulfida dan refraktori yaitu mengubah dari sifat sulfida menjadi oksida. Pada proses roasting, besi, sulfur dan karbon yang ada di dalam bijih dikonversi menjadi besi oksida $\left(\mathrm{Fe}_{2} \mathrm{O}_{3}\right)$, sulfur dioksida $\left(\mathrm{SO}_{2}\right)$, karbon monoksida (CO) dan karbon dioksida $\left(\mathrm{CO}_{2}\right)$ sebagaimana reaksi yang ditunjukkan pada Persamaan (1), (2) dan (3).

$$
\begin{aligned}
& 2 \mathrm{FeS}_{2}+2 \mathrm{O}_{2}(\mathrm{~g}) \rightarrow 2 \mathrm{FeS}+2 \mathrm{SO}_{2}(\mathrm{~g}) \\
& \Delta \mathrm{G}_{677 \mathrm{~K}}^{\mathrm{o}}=-423,70 \mathrm{~kJ} / \mathrm{mol} \\
& \mathrm{FeS}+2 \mathrm{O}_{2}(\mathrm{~g}) \rightarrow \mathrm{FeSO}_{4} \\
& \Delta \mathrm{G}^{\mathrm{o}}{ }_{775 \mathrm{~K}}=-557,62 \mathrm{~kJ} / \mathrm{mol} \\
& 2 \mathrm{FeSO}_{4} \rightarrow \mathrm{Fe}_{2} \mathrm{O}_{3}+\mathrm{SO}_{2}(\mathrm{~g})+\mathrm{SO}_{3}(\mathrm{~g}) \\
& \Delta \mathrm{G}^{\mathrm{o}}{ }_{1173 \mathrm{~K}}=-70,87 \mathrm{~kJ} / \mathrm{mol}
\end{aligned}
$$

Pada penelitian sebelumnya telah dilakukan karakterisasi bijih emas dari tambang Tanggamus 
dengan menggunakan berbagai metode analisis. Disimpulkan bahwa tipe bijih emas yang ditemukan adalah tipe bijih refraktori dengan kadar sulfur di atas 13\% (Mufakhir dkk., 2018). Penelitian ini merupakan penelitian lanjutan yang akan mempelajari pelarutan emas dari konsentrat emas hasil proses roasting dari berbagai variasi temperatur. Pelarutan emas dilakukan dengan memperhatikan pengaruh dari penambahan konsentrasi reagen tiosianat dan oksidator, sehingga dapat diketahui unjuk kerja dari setiap perlakuan.

\section{Metode Penelitian}

\subsection{Bahan penelitian}

Penelitian ini menggunakan bijih emas dari tambang emas di Lengkukai, Kelumbayan Barat, Kabupaten Tanggamus, Propinsi Lampung, yaitu bijih emas tipe refraktori yang karakteristik bijihnya telah dilaporkan oleh Mufakhir dkk. (2018) dengan kadar $\mathrm{Au}$ sebesar 4,03 ppm. Sebanyak $14 \mathrm{~kg}$ bijih emas dikominusi menggunakan alat Jaw Crusher (untuk peremukan), kemudian di Ball Mill (untuk penghalusan) dan diayak menggunakan tyler wire mesh hingga mendapatkan ukuran dibawah 53 $\mu \mathrm{m}$. Proses roasting dilakukan dalam muffle furnace dengan temperatur maksimal $1200{ }^{\circ} \mathrm{C}$. Pelarutan emas dilakukan menggunakan gelas beaker $100 \mathrm{ml}$ yang ditutup dengan plastik wrap dan disimpan di atas alat hot plate dengan pengaduk magnet. Semua bahan kimia yang digunakan merupakan analytical grade dari Merck Jerman dengan reagen pelindi kalium tiosianat (KSCN; $99 \%$ ) dan oksidator ion $\mathrm{Fe}^{3+}$ dari $\mathrm{FeCl}_{3} \cdot 6 \mathrm{H}_{2} \mathrm{O}(99 \%)$ yang dilarutkan dalam aquades.

\subsection{Cara Penelitian}

Sampel pertama dari bijih emas yang sudah dikominusi dan diayak diambil menggunakan metode coning quartering hingga diperoleh sampel yang representatif. Satu bagian hasil pengambilan sampel pertama kemudian diambil kembali dengan metode grab sampling yang digunakan sebagai umpan roasting. Sebanyak 100 gram hasil dari pengambilan sampel kedua dimasukkan ke dalam muffle furnace dengan waktu tinggal selama 2 jam untuk setiap variasi temperatur (Tabel 1). Pada konsentrat emas hasil roasting kemudian dilakukan pemisahan magnetik menggunakan batang magnet berkekuatan 500 gauss dengan metode basah hingga mendapatkan konsentrat magnet (M) dan non magnet (NM). Sebanyak 14 gram dari masing-masing konsentrat kemudian dilindi ke dalam $56 \mathrm{ml}$ larutan kalium tiosianat $0,2 \mathrm{M}$ dan oksidator besi (III) klorida $0,05 \mathrm{M}$ selama 24 jam pada temperatur $85{ }^{\circ} \mathrm{C}$ dengan kecepatan pengadukan $200 \mathrm{rpm}$ untuk medapatkan kondisi temperatur roasting terbaik. Hasil terbaik percobaan tersebut akan dijadikan dasar untuk percobaan pelarutan emas berikutnya, yaitu percobaan pengaruh konsentrasi reagen dan oksidator dengan variasi variabel seperti disajikan pada Tabel 1. Semua konsentrat dianalisis menggunakan $X$-ray Fluorescence (XRF) PANanalytical type Epsilon 3 XLE dan $X$ ray Diffraction (XRD) PANalytical tipe X'Pert3 Powder, sedangkan filtrat emas dianalisis menggunakan Atomic Absorption Spectrometer (AAS) Shimadzhu type AA-7000.

Tabel 1. Variasi variabel percobaan pelarutan emas dari konsentrat emas

\begin{tabular}{lc}
\hline \multicolumn{1}{c}{ Parameter } & Nilai \\
\hline Temperatur Roasting $\left({ }^{\circ} \mathrm{C}\right)$ & $650 ; 750 ; 850 ; 950$ \\
Konsentrasi $\mathrm{KSCN}\left(\mathrm{M}^{*}\right)$ & 0,$1 ; 0,2, ; 0,3$ \\
Konsentrasi $\mathrm{FeCl}_{3}\left(\mathrm{M}^{*}\right)$ & 0,$05 ; 0.1 ; 0,2$ \\
\hline
\end{tabular}

$* \mathrm{M}=$ Molaritas (mol/liter)

\section{Hasil dan Pembahasan}

\subsection{Pengaruh Temperatur Roasting terhadap Pelarutan Emas}

Gambar 1 menunjukkan hasil proses pelarutan $\mathrm{Au}$ pada berbagai temperatur konsentrat non magnetik (NM) dan magnetik (M) terhadap waktu dibandingkan dengan bijih (raw). Pada Gambar 1 (a) terlihat bahwa pelarutan emas terjadi selama rentang 24 jam, pada temperatur roasting $950{ }^{\circ} \mathrm{C}$ selama 12 jam didapatkan pelarutan emas yang paling tinggi yaitu sebesar $0,95 \mathrm{mg} / \mathrm{L}$. Namun sampai dengan waktu 24 jam terjadi penurunan pelarutan emas di semua variasi temperatur kecuali pada temperatur $850{ }^{\circ} \mathrm{C}$. Di lain pihak, pada Gambar 1(b) terlihat 
bahwa tidak terjadi pelarutan emas pada semua variasi temperatur selama rentang waktu 24 jam.

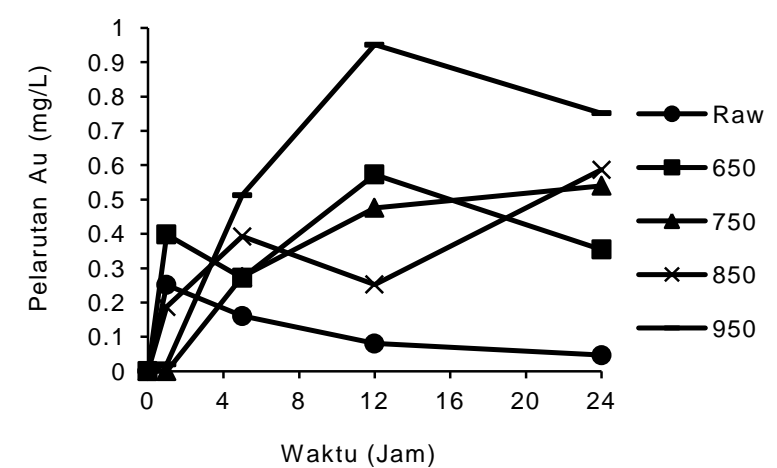

(a)

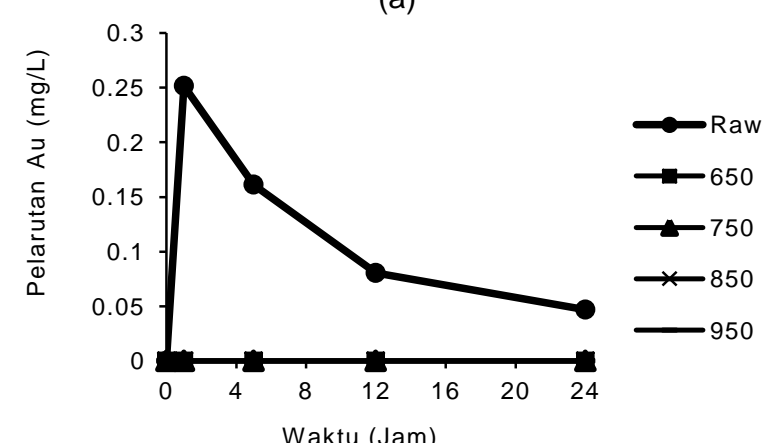

(b)

Gambar 1. Pelarutan emas dari (a) Konsentrat NM, (b) Konsentrat $M$ pada berbagai temperatur Roasting terhadap waktu dibandingkan dengan bijih (raw)

Umpan pelindian dari bijih (raw) tidak menunjukkan performa yang bagus, yaitu hanya mampu melarutkan sampai 0,25 ppm Au. Berdasarkan hasil pelindian tersebut dapat dilihat bahwa logam emas berasosiasi dengan konsentrat NM yang bersifat non magnetik, tidak munculnya senyawa sulfida dibandingkan konsentrat $M$ yang bersifat magnetik, dan masih terdapat senyawa sulfida. Hal ini dapat disebabkan oleh beberapa hal: 1) kandungan sulfur pada konsentrat NM jauh sangat rendah $(0,214 \mathrm{ppm})$ dibandingkan dengan konsentrat $M$ yang masih sangat tinggi $(543,7 \mathrm{ppm})$, sebagaimana dapat dilihat pada Tabel 2. Hal ini terjadi karena pada saat proses roasting, sulfur dalam pirit lebih banyak teroksidasi, sehingga menjadi oksida hematit dan ini akan lebih mudah untuk larut dalam asam (disajikan pada Gambar 2(c)); 2) kemungkinan partikel emas terjebak dalam matrik silika sehingga pada konsentrat $\mathrm{M}$ emas tidak terlarut sedikitpun; 3) partikel emas yang terjebak dalam matrik pirit terbuka porinya atau terlepas setelah fasenya berubah menjadi oksida. Hasil XRD setelah proses pemisahan magnetik terlihat puncak-puncak baru seperti almandin pada Gambar 2(a) dan pirohitit 5,5C pada Gambar 2(b).

Tabel 2. Hasil analisis XRF bijih emas, konsentrat magnetik dan konsentrat non magnetik hasil roasting pada temperatur $950{ }^{\circ} \mathrm{C}$

\begin{tabular}{cccc}
\hline \multirow{2}{*}{ Unsur* } & \multicolumn{3}{c}{ Kadar (\%) } \\
\cline { 2 - 4 } & $\begin{array}{c}\text { Bijih } \\
\text { Emas }\end{array}$ & $\begin{array}{c}\text { Konsentrat } \\
\text { M }\end{array}$ & $\begin{array}{c}\text { Konsentrat } \\
\text { NM }\end{array}$ \\
\hline $\mathrm{Al}$ & 9,20 & 7,99 & 7,83 \\
$\mathrm{Si}$ & 34,34 & 29,06 & 43,72 \\
$\mathrm{P}$ & 0,47 & 0,22 & 0,19 \\
$\mathrm{~S}$ & 15,14 & $543,70 * *$ & $0,21^{* *}$ \\
$\mathrm{~K}$ & 3,34 & 3,38 & 2,68 \\
$\mathrm{Ca}$ & 1,11 & 1,17 & 0,51 \\
$\mathrm{Mn}$ & 0,50 & 1,02 & 0,43 \\
$\mathrm{Fe}$ & 33,00 & 53,82 & 40,08 \\
\hline
\end{tabular}

* sebagian unsur tidak ditampilkan

** satuan dalam ppm

Masih adanya unsur Fe pada konsentrat NM dikarenakan kekuatan magnet yang lemah pada proses pemisahan magnetik, walaupun penggunaan metode basah lebih baik dari pada metode kering (Hredzak Slavomi dkk., 2006). Nampak muncul fase baru yaitu almandin (alumunium fero silikat) yang termasuk sub kelas nesosilikat dengan sifat magnet yang lemah dan silika yang lebih banyak muncul pada pola difraksi. Sedangkan pada konsentrat M dengan unsur Fe dan $\mathrm{S}$ yang lebih besar dibandingkan konsentrat NM, muncul fase baru yaitu pirohitit yang mempunyai sifat magnet yang cukup besar dan termasuk ferrimagnetik. Pada konsentrat hasil roasting $950{ }^{\circ} \mathrm{C}$ tanpa pemisahan magnetik terlihat fase pirit telah hilang dan berubah menjadi hematit karena proses oksidasi sulfur dibandingkan dengan bijih emas (raw). Walaupun demikian, keberadaan partikel emas dalam konsentrat NM perlu dikonfirmasi dengan metode analisis mineralogi dan Scanning Electron Microscope (SEM) dengan Back Scatered Electron (BSE) serta Energy Dispersive $X$-Ray (EDX) Mapping sehingga diketahui karakter emas yang diperoleh. 


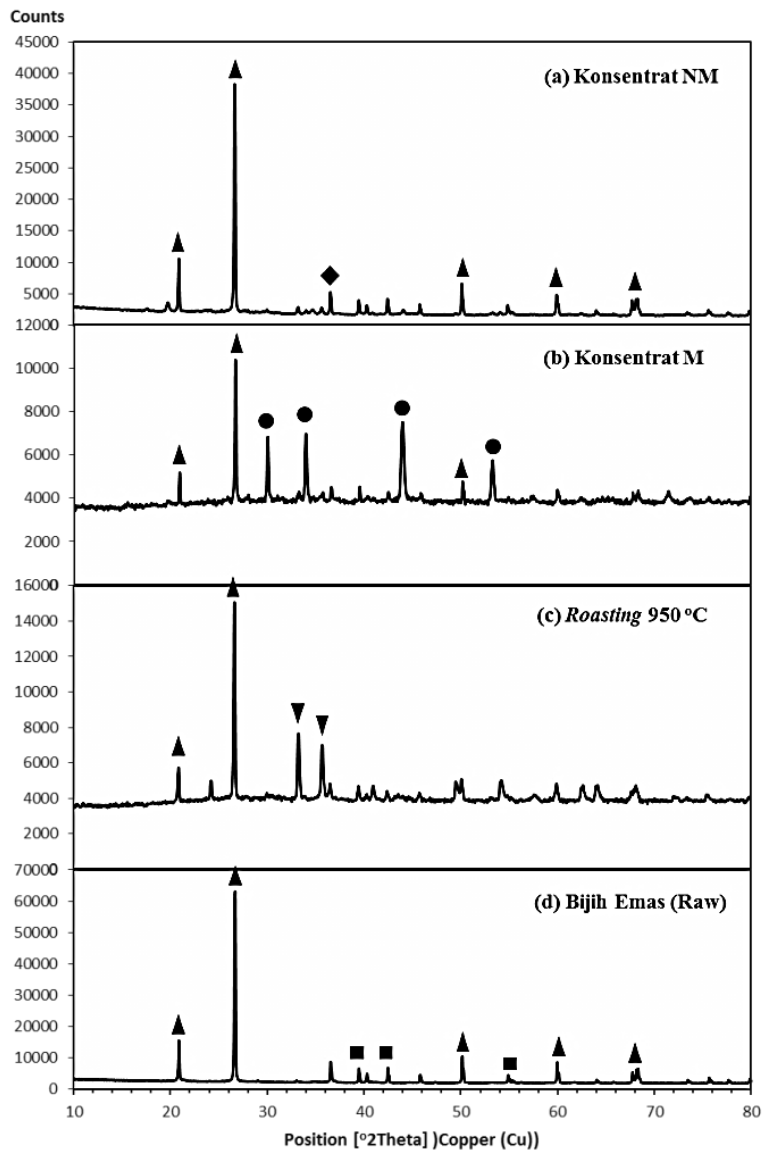

$\Delta$ Silika $\left(\mathrm{SiO}_{2}\right) \square$ Pirit $\left(\mathrm{FeS}_{2}\right) \bigcirc$ Pirohitit 5,5C $\left(\mathrm{Fe}_{0,91} \mathrm{~S}\right)$

$\nabla$ Hematit $\left(\mathrm{Fe}_{2} \mathrm{O}_{3}\right) \Delta \operatorname{Almandin}\left(\mathrm{Al}_{2} \mathrm{Fe}_{3} \mathrm{O}_{12} \mathrm{Si}_{3}\right)$

Gambar 2. Perbandingan pola XRD dari (a) konsentrat $\mathrm{NM}$, (b) konsentrat $\mathrm{M}$, (c) roasting $950{ }^{\circ} \mathrm{C}$ dan (d) bijih emas.

\subsection{Produksi Hidrogen}

Hasil dari pengaruh oksidator ion $\mathrm{Fe}^{3+}$ dalam larutan tiosianat 0,2 M, dengan konsentrat NM temperatur roasting $950{ }^{\circ} \mathrm{C}$ ditunjukkan pada Gambar 2. Berdasarkan Gambar 3 didapatkan pelarutan emas tertinggi terjadi pada waktu 12 jam dengan konsentrasi $\mathrm{FeCl}_{3}$ sebesar $0,1 \mathrm{M}$ dengan nilai $2,29 \mathrm{mg} / \mathrm{L}$. Namun pada waktu 24 jam terjadi penurunan nilai konsentrasi pada pelarutan emas di semua variasi konsentrasi oksidator. Hal ini kemungkinan disebabkan kompleksasi antara tiosianat dengan ion $\mathrm{Fe}^{3+}$ lebih lemah dibandingkan dengan tiosianat dan emas (Jinsan Li dkk., 2011). Penambahan konsentrasi ion $\mathrm{Fe}^{3+}$ tidak memberikan pengaruh yang besar terhadap peningkatan pelarutan emas.

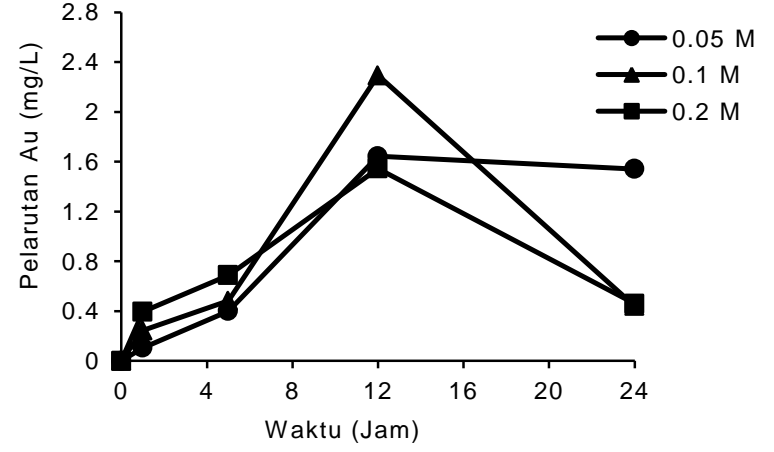

Gambar 3. Pelarutan emas dari konsentrat NM dengan temperatur roasting $950{ }^{\circ} \mathrm{C}$ pada berbagai variasi konsentrasi $\mathrm{FeCl}_{3}$ terhadap waktu.

Rasio molar tinggi tidak meningkatkan pelarutan emas. Hasil penelitian ini sesuai dengan (Jinsan Li dkk., 2011) yang menunjukkan bahwa konsentrasi optimum terjadi pada $0,1 \mathrm{M}$ dibandingkan dengan $0,05 \mathrm{M}$ dan $0,2 \mathrm{M}$ pada pelarutan logam emas (kemurnian emas >99,9; diameter $14,0 \mathrm{~mm}$ ). Hal ini disebabkan ion $\mathrm{Fe}^{3+}$ yang dibutuhkan sudah mencapai titik jenuh sehingga hanya diperlukan konsentrasi $\mathrm{FeCl}_{3}$ yang tepat. Mekanisme pelarutan emas dengan oksidator besi III-tiosianat berkaitan dengan reduksi, dengan $\mathrm{Fe}^{3+}$ secara spontan menjadi $\mathrm{Fe}^{2+}$ saat mengoksidasi $\mathrm{SCN}^{-}$seperti pada Persamaan (4) (Filho, 1994).

$$
\mathrm{Au}+4 \mathrm{SCN}+3 \mathrm{Fe}^{3+} \rightleftharpoons \mathrm{Au}(\mathrm{SCN})_{4}^{-}+3 \mathrm{Fe}^{2+}
$$

\subsection{Pengaruh Konsentrasi Pelarut terhadap Pelarutan Emas}

Hasil dari pengaruh konsentrasi pelarut dengan oksidator ion $\mathrm{Fe}^{3+} 0,1 \mathrm{M}$, dengan konsentrat $\mathrm{NM}$ temperatur roasting $950{ }^{\circ} \mathrm{C}$ ditunjukkan pada Gambar 4. Gambar 4 menunjukkan bahwa semakin besar konsentrasi kalium tiosianat maka akan semakin besar pula konsentrasi pelarutan emas dari konsentrat NM (Marsden dan C. Lain, 2009). Peningkatan nilai pelarutan dicapai pada waktu optimum yaitu 12 jam yaitu sebesar $2,25 \mathrm{mg} / \mathrm{L}$ pada konsentrasi 0,3 M. 


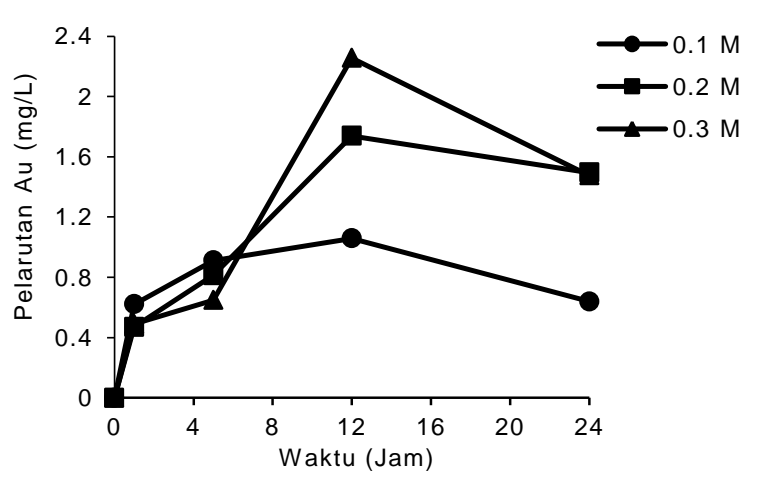

Gambar 4. Pelarutan emas dari konsentrat NM dengan temperatur roasting $950{ }^{\circ} \mathrm{C}$ pada berbagai variasi konsentrasi kalium tiosianat terhadap waktu

Laju pelarutan meningkat sampai dengan 12 jam dan setelah itu tidak ada penambahan melainkan terjadi penurunan. Penurunan tersebut disebabkan penggunaan temperatur pada pelarutan cukup tinggi sehingga menyebabkan sebagian air dalam larutan menguap dan meningkatkan persentase padatan serta meningkatkan viskositas. Laju pelindian menurun dengan penurunan volume cairan (Habashi, 1993). Peningkatan pelarutan pada konsentrasi yang lebih tinggi disebabkan semakin banyak kesempatan kontak antara emas dan tiosianat.

\section{Kesimpulan}

Penelitian ini menunjukkan bahwa pelarutan emas dari bijih emas Lengkukai akan efektif apabila melalui proses pra-pengolahan terlebih dahulu, yaitu melalui proses roasting dan pemisahan magnetik. Penambahan konsentrasi oksidator $\mathrm{Fe}^{3+}$ yang tinggi tidak memberikan pengaruh yang signifikan terhadap pelarutan emas. Di lain pihak, penambahan konsentrasi reagen tiosianat menunjukkan hubungan linier terhadap pelarutan emas. Secara umum laju kinetika pelarutan emas menggunakan tiosianat berjalan lambat dan efektif sampai dengan 12 jam.

\section{Ucapan Terimakasih}

Penulis mengucapkan terima kasih kepada Lembaga Ilmu Pengetahuan Indonesia, khususnya Balai Penelitian Teknologi Mineral yang telah menyediakan dana, tempat, dan peralatan penelitian.

\section{Daftar Pustaka}

Adams, M., 2015, Advances in Gold Ore Processing, Mutis Liber Pty Ltd., Western Australia

Badan Geologi Kementrian ESDM., 2017, Executive Summary Pemutakhiran Data dan Neraca Sumber Daya Mineral Status 2016, Jakarta.

Badan Standar Nasional, 1998, Klarifikasi Sumberdaya Mineral dan Cadangan Amandemen 1, SNI-13-4726-1998.

Barbosa-Filho, O., and Monhemins, A.J., 1994, Iodide-thiocyanate leaching system for gold, Hydrometallurgy '94, Springer, Dordrecht

Baghalha, M., 2012, The leaching kinetics of an oxide gold ore with iodide/iodine solutions, Hydrometallurgy, 113-114, 42-50.

Data LEADS Asia News Network, Six countries produce $91 \%$ of gold in Asia, diambil dari http://www.nationmultimedia.com/detail/aec/ 30300363, diakses pada tanggal 15 November 2018.

Feceriova, J., Balaz, P., and Villachica, C. L., 2005, Thiosulfate leaching of silver, gold and bismuth from a complex sulfide concentrates, Hydrometallurgy, 77, 35-39.

Feng, D., and Deventer, J.S.J.V., 2007, The role of oxygen in thiosulphate leaching of gold, Hydrometallurgy, 85, 193-202.

Feng, D., and Deventer, J.S.J.V., 2011, Thiosulphate leaching of gold in the presence of orthophosphate and polyphosphate, Hydrometallurgy, 106, 38-45.

Handayani, S., dan Suratman., 2017, Biooksidasi: Teknologi Alternatif Pengolahan Bijih Emas Refraktori, Bandung: Puslitbang Teknologi Mineral dan Batubara, 13(3), 197 - 211.

Habashi, F., 1993, A Textbook of Hydrometallurgy, Métallurgie Extractive Quebec, Canada.

Hredzák, S., Tomanec, R.A., Matik, M., Šepelák, V., and Václavíková, M., 2006, Magnetic separation and analysis of products obtained from coal-fired power plant fly ashes of 
Nikola Tesla B (Serbia), Journal of Mining and Metallurgy, 42A.

Li, J, Safarzadeh, M.S., Moats, M.S., Miller, J.D., LeVier, K.M., Dietrich, M., and Wan, R.Y., 2012, Thiocyanate hydrometallurgy for the recovery of gold, Part II: The leaching kinetics, Hydrometallurgy, 113-114, 10-18.

Marsden, J. O. and House, C., 2009, The Chemistry of Gold Extraction 2nd Ed., Society for Mining, Metallurgy and Eploration, Inc, Colorado

Monhemius, J., abd Ball, S.P, 1995, Leaching of Dominican gold ores in iodide-catalysed thiocyanate solutions, Mineral Processing and Extractive Metallurgy IMM Transactions Section C, 104, C117-C124

Mufakhir, F. R., Astuti, W., Prasetyo, E., Sumardi, S., Sudibyo, Handoko, A.S., Junaedi, A., Marsas, N. dan Supriyatna, Y. I., 2019, Characterization of gold ore from tanggamus mine lampung province, IOP Conference Series: Materials Science and Engineering 478, 012018.

Orgul S., and Atalay, U., 2002, Reaction chemistry of gold leaching in thiourea solution for a Turkish gold ore, Hydrometallurgy, 67, 71-77.

Setiawan, I., Zulkarnain, I., Indarto, S., and Sudarsono, 2005, Alterasi dan mineralisasi di sayap barat Pegunungan Bukit Barisan: Kasus daerah Kota Agung dan sekitarnya Kabupaten Tanggamus - Propinsi Lampung, Jurnal RISET Geologi dan Pertambangan, 15 (1), 1326.

Somasundaran, P. and Wang, D., 2006, Solution Chemistry: Minerals and Reagents, Elsevier, Amsterdam.

Sokic, M., Ilic, I., Zivkovic, D., and Vuckovic, N., 2008, Investigation of mechanism and kinetics of chalcopyrite concentrate oxidation process, Metalurgija, 47 (2), 109-113.

Yang, X., Moats, M. S., Miller, J.D., Wang, X., Shi, X., and $\mathrm{Xu}, \mathrm{H} ., 2010$, Thiourea thiocyanate leaching system for gold, Hydrometallurgy, 106 (1-2), 58-63

Yannopolous, J. C., 1991, The Extractive Metallurgy of Gold, Springer US, New York. 